\title{
El Campo de la Discapacidad Desde la Perspectiva de los Docentes Que Cursan la Especialización en Actividad Física Adaptada Y DiscapaCidad Del IUACJ ${ }^{1}$
}

The Field of Disability from the Perspective of the Teachers ENROLLED in the Adapted Physical Activity and Disability Specialization Course of THE IUACJ

\author{
Sofía RUBINSTEIN ${ }^{2}$ \\ Vanessa FRANCO ${ }^{3}$
}

\begin{abstract}
RESUMEN: La primera edición de la especialización en actividad física adaptada y discapacidad se constituye en un hito por ser el primer posgrado de estas características en Uruguay. Esto implica pensar la formación de los docentes a partir de escenarios y poblaciones diversos. Nos planteamos analizar la formación y trayectoria laboral en el campo de la discapacidad, así como las concepciones de inclusión y discapacidad de once estudiantes que cursan el posgrado. Los datos fueron recolectados a través de la entrevista semi-estructurada. Los resultados muestran que sólo cinco docentes tienen formación previa en el área de la discapacidad y seis de ellos experiencia en el trabajo con personas con discapacidad. Todos entienden la importancia de formarse para tener herramientas que les permitan intervenir de mejor manera es sus prácticas. Las concepciones de discapacidad e inclusión muchas veces transitan por el paradigma médico rehabilitador y de educación especial, pero a pesar de ello, presentan actitudes positivas ante el reto de trabajar con la diversidad del alumnado.
\end{abstract}

PALABRAS CLAVE: Formación de posgrado. Docentes. Discapacidad. Actividad física adaptada.

\begin{abstract}
The first edition of the specialization in adapted physical activity and disability is a milestone as it is the first graduate program with these characteristics in Uruguay. This implies in thinking the teacher training from different scenarios and populations. We set out to analyze the training and career path in the field of disability, as well as the inclusion and disability conceptions of eleven students who attend the graduate course. The data was collected through the semi-structured interview. Results show that only five teachers had previous formation in the area of disability and six of them had experience of working with people with disabilities. Everyone understands the importance of training to have the tools that will allow them to intervene in a better way in their practices. Conceptions of disability and inclusion often go through the medical and special education paradigm of rehabilitation, but, despite this, they present positive attitudes in relation to the challenge of working with the diversity of the students.
\end{abstract}

KEYWORDS: Graduate training. Teachers. Disability. Adapted physical activity.

\section{INTRODUCCIÓN}

En Uruguay, las personas en situación de discapacidad alcanzan el 16,4\% de la población (Nuñez, 2014), constituyéndose en un sector de la población vulnerable con pocas posibilidades de inclusión laboral, social y educativa. Al igual que varios países de la región, se ha avanzado en los apoyos a este colectivo y ejemplo de ello son la ratificación de la Convención sobre los Derechos de las Personas con Discapacidad (CDPD) en el año 2008, y la creación de normativas con relación a la protección de los derechos de las personas con discapacidad como la Ley 18.651 del año 2010. Sumado a ello, en las últimas décadas los movimientos sociales

\footnotetext{
${ }^{1}$ http://dx.doi.org/10.1590/s1413-65382620000100002

${ }^{2}$ Magister en Ciencias del Movimiento Humano (Escola de Educação Física da Universidade Federal do Rio Grande do Sul ESEF - UFRGS - Brasil). Facultad de Educación Física (Instituto Universitario Asociación Cristiana de Jóvenes - IUACJ) - Uruguay. E-mail: sofiar@adinet.com.uy. ORCID: https://orcid.org/0000-0003-0931-3022

${ }^{3}$ Magister en Actividad Física y Salud (Fundación Universitaria Iberoamericana - FUNIBER). Facultad de Educación Física (IUACJ) - Uruguay. E-mail: vfranco81@hotmail.com. ORCID: https://orcid.org/0000-0001-5569-1003
} 
integrados por personas con discapacidad y/o sus familias, han golpeado puertas exigiendo que se cumplan sus derechos, entre los que se destaca el acceso (ingreso, permanencia y egreso) en el sistema educativo. En este sentido, la inclusión es un "proceso democrático integral que involucra la superación efectiva de las condiciones políticas, económicas, sociales y culturales que producen históricamente la exclusión" (Gentili, 2009, p. 35).

Acercarse a definir la discapacidad, implica hacer referencia a dos conceptos actuales de organismos internacionales. Por un lado, la CDPD establece que la discapacidad resulta de la interacción entre la persona con deficiencia y las barreras debidas a la actitud y al entorno (barreras físicas, actitudinales, de la comunicación y de acceso a la información (Organización de las Naciones Unidas [ONU], 2006). Por otra parte, en la Clasificación Internacional de Funcionamiento, de la Discapacidad y de la Salud (CIF), la discapacidad es vista como un término genérico que abarca deficiencias, limitaciones de la actividad y restricciones a la participación. En este caso, el funcionamiento y la discapacidad son vistas como una interacción dinámica entre los estados de salud y los factores contextuales (Organización Mundial de la Salud [OMS], 2001, p. 9) Las dos clasificaciones tienen orígenes distintos: la primera de ellas se basa en un modelo explicativo social, mientras que la segunda en el modelo bio-psico-social (Bagnato, 2017).

Ambas definiciones coinciden en tres aspectos: 1. La situación de discapacidad tiene su origen en la condición de salud de una persona (presencia de deficiencias sensoriales, mentales, físicas, intelectuales en tiempo prolongado). 2. La discapacidad no es una situación personal de un sujeto, sino que se produce en la interacción con el ambiente. 3. Ambas clasificaciones (CDPD y CIF) son acuerdos generales que cada país necesita adaptar a su realidad, a su contexto (Bagnato, 2017).

En este marco, desde el ámbito académico es importante garantizar las oportunidades de las personas con discapacidad en el ejercicio de sus derechos. En lo que refiere a la educación física y sus áreas afines, en Uruguay han crecido en cantidad y calidad las propuestas de Educación Física adaptada, Deporte adaptado, Educación Física inclusiva, Deporte inclusivo, recreación inclusiva, entre otras, acompañando las políticas sociales y educativas vigentes, lo que genera un campo de actuación profesional extenso y complejo en el que intervienen un conjunto diverso de profesionales de distintas áreas y en el que participan docentes de Educación Física.

Los docentes son una pieza decisiva en la participación de personas con discapacidad en la Educación Física formal y no formal. Numerosos estudios muestran la importancia del docente en la inclusión de estudiantes con discapacidad (Castillo, 2016; Espinoza de los Monteros, 2017; González \& Macías, 2018; Plancarte, 2017) a través del desarrollo de estrategias pedagógicas que respondan a la diversidad del alumnado, donde se incluyen la selección de los objetivos, las metodologías de enseñanza, las actividades, los tipos de evaluación y el empleo de apoyos cuando sea necesario, la elección y adecuación de los materiales. Sin embargo, la responsabilidad no es únicamente del docente, sino que todos los integrantes de la institución y comunidad tienen que involucrarse activamente para eliminar las barreras que impidan la participación de estudiantes (Barrio, 2009; Crisol, 2019). 
Nos hemos detenido en la formación docente, porque se ha identificado como una de las barreras para la participación de estudiantes con discapacidad. Valdés y Monereo (2013) plantean que en este nuevo modelo tendiente a la inclusión, el docente debe enfrentarse a situaciones muchas veces inesperadas, para las cuáles no cuenta con las herramientas necesarias. Los docentes no se sienten preparados para afrontar la diversidad en sus clases y entienden que la incorporación de contenidos sobre estrategias pedagógicas en la formación de grado, impactaría en forma positiva en el quehacer docente (Velásquez, Quiceno, \& Tamayo, 2016) y en las actitudes frente a la discapacidad (González \& Macías, 2018). Ampliando el foco de atención del docente, estudios elaborados por Rello y Garoz (2014), Abellán, Sáez-Gallego y Reina (2018), Rello, Garoz y Tejero (2018) pusieron la mirada en programas de actividad física y deporte inclusivo para la sensibilización y el cambio de actitudes hacia la discapacidad de alumnos de enseńanza primaria y secundaria. Los resultados muestran que el contacto cercano, el compartir experiencias y deportes con personas con discapacidad mejoran las actitudes hacia la discapacidad. Sumado a ello, los efectos positivos y la perdurabilidad de los cambios están asociados al tiempo de intervención de los programas.

Las propuestas de Educación Física y deportivas planificadas por los docentes con el objetivo de sensibilizar y crear espacios de participación de todos los estudiantes se constituyen en motores de cambio. Los profesores junto a otros actores, son los encargados de proporcionar entornos de aprendizaje que fomenten la inclusión de todos los alumnos, y así generar espacios para el cambio de actitudes hacia la discapacidad.

Por estos motivos, resulta oportuno tratar la formación en actividad física adaptada en los cursos de grado y posgrado y es en esta línea que la Facultad de Educación Física del IUACJ viene trabajando.

La Especialización en actividad física adaptada y discapacidad se encuentra dentro de las propuestas de posgrados del IUACJ y es la primera y única en Uruguay. Propone la articulación entre el conocimiento y la realidad de la actividad física adaptada en contextos diversos y comenzó a desarrollarse en mayo del año 2018 con el ingreso de la primera generación.

En términos académicos, la especialización se justifica en la medida en que plantea en un mismo posgrado diferentes enfoques en el abordaje de las discapacidades, considerando las características, los contextos y las actividades, así como las teorías y conceptualizaciones que giran en torno a la discapacidad, buscando superar tanto la mera yuxtaposición de conocimientos como su reducción a la interpretación técnica.

Consideramos a los docentes como actores sociales que tienen su accionar influenciado culturalmente. Expresan en sus prácticas docentes determinados valores y concepciones de acuerdo con los contextos en el que se constituyeron, como la preparación profesional a la cual tuvieron acceso, el contexto educativo en que el trabajaron y los lazos interpersonales que mantuvieron. En este sentido, entendemos relevante indagar en las concepciones de discapacidad e inclusión, perfil laboral y experiencias previas en el campo de la discapacidad, así como los motivos en la elección de este campo profesional y de formación, de los estudiantes que cursan la especialización en actividad física adaptada y discapacidad del IUACJ, que se constituyen en la primera generación del posgrado y que decidieron cursar la especialización como una opción personal de formación. 


\section{MéTodo}

La perspectiva metodológica elegida es la cualitativa (Sautu, 2003) y la investigación alcanza un nivel descriptivo. Participaron del estudio once estudiantes que cursan el posgrado de especialización en actividad física adaptada y discapacidad del IUACJ de un total de trece que se encuentran inscriptos. Este primer grupo de estudiantes presenta características heterogéneas, con edades, experiencias laborales y recorridos a nivel de formación diversos.

Se seleccionó la entrevista semi-estructurada como instrumento de recolección de datos, lo que permite un diálogo fluido con los sujetos del estudio (Marradi, Archenti, \& Piovani, 2007). La elección del instrumento estuvo determinada por el interés de las investigadoras y por las características del contexto en donde se desarrolló el estudio. La información recolectada fue analizada a través de dos categorías de análisis, construidas a partir de los objetivos del estudio, la teoría existente en relación al tema y las pautas de las entrevistas. Para respetar el anonimato de los participantes optamos por asignar un número a cada uno de los sujetos del estudio: Entrevistado 1 (E1), Entrevistado 2 (E2) ... Aplicamos y testeamos la pauta de la entrevista por medio de un estudio piloto antes del inicio de la recolección de datos del estudio principal. Luego de elaborada la pauta del instrumento y previo a recolectar los datos, el proyecto fue elevado al Comité de Ética del IUACJ para su aprobación.

\section{Resultados y discusión}

En este apartado presentamos y discutimos en conjunto los datos agrupados en dos categorías de análisis: formación académica, trayectoria laboral y motivos de elección de este campo profesional; concepciones de discapacidad e inclusión.

\subsection{Formación ACADÉMICA, TRAYECTORIA LABORAL Y MOTIVOS DE ELECCIÓN DE ESTE CAMPO PROFESIONAL}

Todos los estudiantes que participaron del estudio tienen formación docente, diez son Profesores o Licenciados en Educación Física (la titulación depende del plan de estudios que cursaron) y uno es Técnico en Atletismo. Por normativas del Ministerio de Educación y Cultura de Uruguay para acceder a cursar una especialización, los postulantes tienen que tener aprobada una formación de grado universitaria o terciaria. Por tanto, un estudiante accede a cursar el Diploma en actividad física adaptada y discapacidad pero no la especialización, constituyéndose en un curso de menor duración en cuanto a cantidad de asignaturas, carga horaria y duración del posgrado.

Esta primera generación del posgrado se conformó exclusivamente con docentes del campo de la Educación Física que tienen entre 2 y 28 años de recibidos. A continuación presentamos el Cuadro 1, que contiene información sobre la titulación y la cantidad de años que tiene en el ejercicio profesional, la formación complementaria y la experiencia laboral en el área de la discapacidad. 


\begin{tabular}{|c|c|c|c|c|}
\hline & Titulación & $\begin{array}{l}\text { Años de } \\
\text { titulado }\end{array}$ & $\begin{array}{c}\text { Formación complementaria } \\
\text { en discapacidad }\end{array}$ & $\begin{array}{l}\text { Experiencia laboral en } \\
\text { el área de la discapacidad }\end{array}$ \\
\hline E1 & $\begin{array}{l}\text { Técnico en } \\
\text { atletismo }\end{array}$ & 17 años & Sí. Varias discapacidades & $\begin{array}{l}\text { Si. Pista de atletismo con } \\
\text { alumnos con discapacidad }\end{array}$ \\
\hline E2 & Licenciado en EF & 4 años & No & $\begin{array}{l}\text { No. Educación primaria } \\
\text { común }\end{array}$ \\
\hline E3 & Licenciado EF & 2 años & No & $\begin{array}{l}\text { No trabaja en el área de } \\
\text { la EF }\end{array}$ \\
\hline E4 & Profesor de EF & 26 años & Sí. Varias discapacidades & $\begin{array}{l}\text { Si. Directora de plaza de } \\
\text { deportes }\end{array}$ \\
\hline E5 & Licenciado en EF & 12 años & No & $\begin{array}{l}\text { No. Educación primaria y } \\
\text { secundaria común }\end{array}$ \\
\hline E6 & Licenciado en EF & 2 años & No & $\begin{array}{l}\text { Si. Institución donde viven } \\
\text { personas con discapacidad }\end{array}$ \\
\hline E7 & Licenciado en EF & 2 años & No & $\begin{array}{l}\text { No trabaja en el área de } \\
\text { la EF }\end{array}$ \\
\hline E8 & Profesor de EF & 23 años & $\begin{array}{l}\text { Si. Trastorno del espectro } \\
\text { autista e inclusión }\end{array}$ & Si. Escuela especial \\
\hline E9 & Licenciado EF & 12 años & Si. Deportes adaptados & $\begin{array}{l}\text { Si. Centro de rehabilita- } \\
\text { ción }\end{array}$ \\
\hline E10 & Profesor de EF & 28 años & Si. Varias discapacidades & $\begin{array}{l}\text { Si. Centro de rehabilitaci- } \\
\text { ón. Intendencia departa- } \\
\text { mental }\end{array}$ \\
\hline E11 & Licenciado en EF & 14 años & No & $\begin{array}{l}\text { No. Educación primaria } \\
\text { común }\end{array}$ \\
\hline
\end{tabular}

Cuadro 1. Características de los sujetos del estudio.

Fuente: Elaboración propia (2019).

$\mathrm{Al}$ indagar sobre la formación complementaria, cinco entrevistados tienen cursos de actualización docente vinculados a la discapacidad, mientras que el resto, la especialización en actividad física adaptada y discapacidad se presenta como la primera instancia de formación en el área. Un estudio elaborado por Santos, Funes y Ferreira (2015), sobre la formación continua en el área de la educación especial ${ }^{4}$ de docentes de Portugal, obtuvo como resultados que el $70 \%$ de los docentes que participaron de la investigación no recibieron o participaron de cursos de formación permanente. Los resultados de ambos estudios preocupan, si pensamos que los docentes tienen que buscar alternativas que intenten eliminar las barreras en la enseñanza de alumnos con discapacidad. Sin embargo, en el caso de los resultados del estudio que aquí presentamos, la especialización es considerada una instancia de formación continua, por lo que la elección en cursarla indica que los docentes están preocupados y ocupados por su formación.

${ }^{4}$ Denominación utilizada por los autores en la investigación. 
Sobre la formación continua de los participantes de la investigación destacamos lo siguiente: "De deporte adaptado hice de bochas, de voleibol adaptado, de natación" (E9); "he hecho varios cursos acá y en otros lados..." (E4); "hice cursos sobre TEA y sobre inclusión y diversidad. Porque en realidad, nuestra generación, no tuvo ningún tipo de formación en el ISEF de especial" (E8).

El E8 plantea un aspecto que es reiterado por otros docentes que participaron del estudio y que tienen más años de antigüedad en la docencia. La inclusión de asignaturas vinculadas a la discapacidad en el Curso de profesores del Instituto Superior de Educación Física (ISEF) se remonta al plan de estudios de 1992, antes de esa fecha los planes de estudio no abordaban la temática. En los sucesivos planes, la temática de la discapacidad estuvo y está presente a través de asignaturas obligatorias u optativas, de tronco común o perfil de centro (Rubinstein, 2012). En el caso de la Licenciatura en Educación Física, Recreación y Deporte del IUACJ, el primer plan de estudios del año 2000 no contemplaba la formación en el campo de la discapacidad, salvo un seminario académico con escasa carga horaria. Con la reformulación del plan de estudios, en el año 2012 se incluyó una asignatura obligatoria de carácter semestral (Instituto Universitario Asociación Cristiana de Jóvenes [IUACJ], 2011). La Licenciatura en Educación Física, Deportes y Recreación de la Universidad de la Empresa de reciente creación, integra en su malla curricular una asignatura denominada Educación Física adaptada ${ }^{5}$.

Con relación a la escasa formación de grado en el área de la discapacidad transcribimos lo siguiente: "tuvimos un taller pero ni siquiera era parte de nuestra formación" (E5); "la formación ha ido cambiando, porque yo arranqué en el '88 a estudiar y era nula, despacito se fue construyendo"(E4).

Sobre este tema Sosa (2010) y Salerno, Jordán y Araújo (2015) comparten la importancia de la formación en el área, pero cuestionan que la misma esté ligada a una única o varias asignaturas específicas en los planes de estudio, asociándolo a una forma de exclusión. Consideran que es más inclusivo trabajar en el abordaje con un eje transversal de la temática, en las distintas asignaturas que componen la malla curricular sin homogeneizar ni generar categorías de sujetos.

En un estudio elaborado por Oliveira, Silva, Padilha y Bomfim (2012) se propuso como objetivo analizar la preparación de los docentes de dos escuelas públicas de Acre (Brasil) con relación a nociones básicas de Lengua de Señas (LIBRAS, sigla en portugués) y Braille. El 45\% de los docentes que participaron de la investigación no conocía la enseñanza de LIBRAS y el 90\% desconocía los métodos de enseñanza en Braille. El gobierno ofreció cursos de capacitación, sin embargo quedó claro que la formación inicial de los docentes era escasa. En otro estudio realizado por Oliveira y Barros (2012) en Bahía (Brasil), la totalidad de los docentes que participaron de la investigación plantearon que la graduación no los preparó para trabajar con estudiantes con discapacidad. Sumado a ello, el 80\% consideró que no existía en ese momento oferta de cursos de capacitación para la atención individualizada especializada. Estos resultados van en la línea de los hallazgos de este trabajo de investigación. El E2 realiza este planteo: "la mayoría de los docentes que están trabajando en el área de la discapacidad no tenian la formación dentro de lo que era la Licenciatura o el Profesorado. Se fueron encontrando con situaciones de alu-

5 Información extraída de la página web: https://ude.edu.uy/fcedu-ude/licenciatura-en-educacion-fisica-deportes-recreacion/ 
mnos con discapacidad y a partir de ahi desarrollaron herramientas. Capaz que con las generaciones pasadas hubo un debe en la formación".

Los docentes también plantean, que muchas veces la formación es adquirida a través de la experiencia y del contacto con personas con discapacidad durante su práctica profesional, por las escasas posibilidades que hay en la formación permanente: "por lo que tengo entendido muchas opciones de formación complementaria no hay" (E7). La opinión del entrevistado es relevante en el entendido que la formación no finaliza en los cursos de graduación, por el contrario, debe estar presente a lo largo de la trayectoria docente (Santos et al., 2015).

En estudios elaborados por Echeita (2013), Colmenero, Pantoja y Pegajalar (2015), González y Macías (2018), González-Gil, Martín-Pastor y Poy Castro (2019), los docentes manifestaron la falta de formación en atención a la diversidad y la escasa capacitación en aspectos pedagógicos que les permitan programar los procesos de enseñanza y aprendizaje, como principales barreras para fomentar la inclusión. En este sentido, aunque los docentes entrevistados manifestaron escasas posibilidades de formación en el área, no se desprenden de sus discursos actitudes negativas ante el área de actuación de la discapacidad, por el contrario, presentan una predisposición a formarse.

Con relación a la trayectoria laboral en el trabajo con personas con discapacidad, los resultados del estudio muestran que seis de los entrevistados, tienen experiencia en el área y cinco de ellos son los que más tiempo llevan en el ejercicio de la profesión (Cuadro 1). Los docentes que no participaron de cursos de actualización docente en el área de la discapacidad, son los que además no tienen experiencia laboral en esta área de actuación, a excepción de un docente que no tiene formación complementaria pero trabaja en un centro específico con personas con discapacidad. Tres docentes trabajan en educación primaria y secundaria donde la diversidad está presente, aunque no siempre desde la perspectiva de la discapacidad: "soy profesor de Educación Física en primaria, en un cargo para una escuela común de Montevideo" (E11); "en escuela especial para niños con discapacidad intelectual, pero las discapacidades son bien diversas..." (E8).

El campo de actuación del profesor de educación física es variado y esto se refleja en las respuestas de los entrevistados. El entrevistado E4 trabaja hace más de 20 años con personas con discapacidad en docencia directa y gestión. Actualmente, como Directora de una plaza de deportes, proyecta y desarrolla políticas de inclusión: "como ahora estoy en un cargo de gestión en la plaza de deportes mi tarea es incluir a todas las personas... ". Por su parte, el E10 explica que trabaja "desde el año 2010 en CEREMA, en rehabilitación en Maldonado por la Secretaria Nacional de Deporte y en la IM Maldonado, trabajo con personas con discapacidades sensoriales y motrices a nivel recreativo, deportivo y competitivo". La relación que existe entre los ańos de ejercicio de la profesión con la experiencia en el trabajo con personas con discapacidad es mencionada en estudios elaborados por Hernández, Labrador, Niort, Berbel y Trullols (2017) y González y Macías (2018) como un aspecto que condiciona de manera positiva las actitudes de los docentes hacia la presencia de estudiantes con discapacidad en las clases.

Los motivos que impulsaron a los entrevistados a trabajar con población con discapacidad son diversos. En varios casos aparece el "desafío personal de tratar de hacer algo en un campo que hay mucho por hacer" (E5); "empecé a trabajar para generar espacios..." (E4); "a veces 
en la vida pasan cosas, uno va teniendo experiencias personales que me llevaron a ver otras áreas" (E6). Otras veces por elección del cargo en el sistema educativo público y privado, por temas económicos, y porque trabajan en la educación formal y asisten estudiantes con y sin discapacidad a las clases: "un poco por elección de la unidad que estaba cuando llegó el momento de elegir el cargo" (E9); "en principio fue una opción laboral mejor. Tenia el trabajo más cerca, habia una serie de compensaciones económicas. Entonces opté por eso en ese momento pero no me arrepiento para nada porque sabia que me iba a gustar" (E8).

Estas opiniones muestran que para los entrevistados no siempre fue una elección pensada trabajar con personas con discapacidad, sino que la propia trayectoria laboral los fue volcando a este campo de actuación. Situación similar ocurre con algunos docentes que participan de una propuesta educativa, que se lleva adelante en el liceo IAVA de la ciudad de Montevideo. Allí estudiantes con discapacidad auditiva participan de algunas clases con estudiantes oyentes y los docentes, muchas veces eligen la unidad de trabajo sin saber que en los grupos hay estudiantes con y sin discapacidad (Ministerio de Educación y Cultura [MEC], 2012).

El contacto con personas con discapacidad, también influye en la elección de esta área de formación y desarrollo profesional y en la construcción de actitudes positivas hacia la discapacidad como lo muestra el E3: "siento mucha empatía desde siempre, tengo un tio y una prima con discapacidad intelectual. Cuando salió la especialización quise formarme en esta área”.

La perspectiva de este entrevistado, podemos relacionarla con un estudio elaborado por Moreno, Rodríguez, Saldaña y Aguilera (2006), sobre las actitudes de estudiantes matriculados en asignaturas relacionadas a la discapacidad de Magisterio (especialidad Educación Especial), Psicopedagogía y Psicología de la Universidad de Sevilla. Los resultados obtenidos mostraron que los estudiantes que tenían contacto directo con personas con discapacidad, manifestaron una actitud positiva mayor en comparación con los que no tenían contacto. Sin embargo, Yuker (1988) plantea algunos reparos al afirmar que el contacto con personas con discapacidad por sí mismo, no significa que la persona sin discapacidad tendrá actitudes positivas. De acuerdo al autor, las consecuencias del contacto con personas con discapacidad sobre las actitudes, están mediatizadas por las características de las personas con discapacidad y sin discapacidad y por la interacción que tengan entre ambas. Y para que la interacción dé lugar a actitudes positivas debe ser estructurada y duradera en el tiempo e implicar la adquisición de un mayor conocimiento entre las personas (González \& Baños, 2012; Rello \& Garoz, 2014; Rello, Garoz, \& Tejero, 2018).

Son varios los autores que asocian las actitudes positivas de profesores en relación a la enseńanza de alumnos con discapacidad con el éxito de programas educativos. A su vez, la predisposición de los docentes para desarrollar su trabajo con personas con discapacidad y aceptar la diversidad en sus clases, está asociado con las reales posibilidades de inclusión de estudiantes con discapacidad en el sistema educativo (Araya-Cortés, González-Arias, \& CerpaReyes, 2014; Bausela, 2008; Martins, 2014; Palla \& Mauerberg-deCastro, 2004) como vimos a lo largo de esta categoría de análisis. 


\subsection{CONCEPCIONES DE DISCAPACIDAD E INCLUSIÓN}

Al indagar sobre las concepciones de discapacidad que tienen los docentes que participaron de la investigación, encontramos en primera instancia dificultades en poder expresar con palabras su visión. Las respuestas muchas veces son confusas y dejan entrever las tensiones entre lo que piensan, vivencian en su práctica profesional y en su cotidiano. Algunos de ellos intentaron acercarse al concepto de la CIF (2001), sin embargo al momento de plasmarlo en palabras, se acercaban más a la clasificación internacional de deficiencia, discapacidad y minusvalía (CIDMM) de la OMS (1983) o al modelo médico rehabilitador de la discapacidad (Palacios, 2008). Las palabras de algunos de los entrevistados indican que: "la discapacidad es una condición de salud relacionada con el entorno y las barreras que ofrece la sociedad. Es la falta de algo en relación a otra cosa"(E7); "su función es diferente" (EG); "algo adquirido, heredado que impide el común funcionamiento en la sociedad" (E9); “que tenga algo que no funcione al 100\%”(E1). Estas construcciones teóricas apuntan al sentido de diferencia otorgado entre las personas con discapacidad y las personas que no tienen discapacidad La diferencia para Vallejos et al. (2015) rememora aquello que le falta al otro para ser como uno mismo, bajo el parámetro de normalidad. En este sentido aparece la comparación con lo que a nivel biológico se considera normal.

Sumado a ello, las concepciones de los entrevistados atraviesan términos que se encuentran en la definición de la CIF, pero inmediatamente pasan al modelo médico al hacer referencia a la falta de algo, poniendo el foco en la persona con discapacidad, como lo plantea el E8: "lo asocio con lo que son las deficiencias, que me falta un brazo, que me falta una pierna"; "la falta de capacidad" (E7). En este modelo, se considera que las causas de la discapacidad son científicas (derivadas en limitaciones individuales de las personas). El problema es la persona, son sus diversidades y dificultades (Palacios, 2008; Urrego Gallego \& Urrego Gallego, 2007; Vallejos et al., 2015). La atención sanitaria es considerada el aspecto primordial y a nivel político, la atención médica es la que necesita ser modificada (Sosa, 2009).

Un estudio elaborado por Fontana-Hernández y Vargas-Dengo (2018), encontró similares resultados en las construcciones conceptuales sobre discapacidad de docentes de la Universidad Nacional de Costa Rica. Los autores plantean que la percepción de discapacidad aparece como una condición individual centrada en la persona, así como la ausencia, carencia o algo que falta para estar completo.

Enmarcados en la CDPD se encuentran las ideas de otros entrevistados: "más allá de la condición de la persona siento que las barreras las pone la sociedad, las pone la familia, el centro educativo" (E3); "la discapacidad, depende de la realidad que viva la persona"(E5); "para mi es un concepto muy social, depende de las barreras arquitectónicas, actitudinales, de las limitaciones del entorno" (E10). De estas opiniones se desprenden las barreras debidas a la actitud y al entorno que evitan la participación plena y efectiva en la sociedad, en igualdad de condiciones con los demás personas (ONU, 2006). Y van en la línea del modelo social de la discapacidad, que entiende que las causas que dan lugar a la discapacidad son fundamentalmente sociales (Arellano, Gaeta, Peralta, \& Cavazos, 2019; Palacios, 2008). Sobre este tema Querejeta (2003) explica que las limitaciones a las que se enfrentan las personas con discapacidad, en términos de educación, empleo, salud, transporte, alojamiento, no son la consecuencia de su situación médica sino la resultante de las actitudes de la población y del abandono socio-político en el que se encuentran. En esta línea y con un enfoque en la educación, se encuentra la opinión del E11: 
"creo que todos los chiquilines tienen distintas formas de aprender. Para mi la discapacidad pasa por algo que genera mayores dificultades en el aprendizaje. A medida que voy adquiriendo mayor formación, logro más el objetivo de incluirlos". Por un lado, el entrevistado tiene muy presente las características de los alumnos, haciendo énfasis en la diversidad y por otro, al docente como figura fundamental del proceso educativo. Y en este sentido, plantea la relación entre la formación docente con el sentido que se le otorga al ejercicio de enseñar. Pone el foco en la eliminación de las barreras (en este caso en la formación docente) sin centrarse en la persona (Bagnato, 2017).

Es interesante destacar los calificativos utilizados por los entrevistados para referirse a la discapacidad. "Patología", "discapacitado", "normal”, "diferente”, "especial", "norma", "desvio", "en desventaja", todos términos con una connotación peyorativa creados a partir de una imagen que la mente construye e influidos fuertemente por las vivencias de cada sujeto. En el ámbito profesional, muchos de los términos citados hacen referencia a concepciones médicas, psicológicas, educativas y sociales ya superadas (Verdugo, 2005), pero que sin embargo se siguen utilizando y probablemente esto suceda, por una formación deficitaria en el ámbito de la discapacidad. El autor agrega que la terminología empleada "expresa la evolución de las actitudes profesionales y sociales, pero los cambios de nombre dejan intactos los prejuicios de la mayor parte de las personas..." (Verdugo, 2005, p. 5). No resulta llamativo entonces que los docentes entrevistados utilicen terminología que responde a determinado momento histórico y modelo de discapacidad, en la medida que al indagar en la formación en el área de la discapacidad plantean que es escasa. Sin restarle importancia a la formación como un elemento clave para mejorar las prácticas docentes, en este caso de estudiantes con discapacidad, tendemos a afirmar que los cambios en la forma de pensar y sentir, no transcurren solamente por la formación. Las creencias, costumbres, valores y actitudes son aspectos claves en los cambios en la perspectiva y la mirada con relación a la discapacidad y tienen una incidencia directa en las prácticas pedagógicas de los docentes. La percepción que los docentes tienen de la discapacidad, los calificativos que utilizan para nombrarla, se constituyen en barreras para el ingreso, el tránsito y el egreso de los estudiantes en el sistema educativo.

Al igual que en las construcciones teóricas sobre la discapacidad, los discursos de los entrevistados con relación a la inclusión son variados y algunas veces poco precisos. Surgen términos como "igualdad", "diversidad", "diferencias" enmarcados en concepciones teóricas que no siempre tienen un anclaje en la realidad cotidiana y educativa. Al respecto, el E6 expresó: "alguien que lo ponés en el mismo lugar a trabajar, de la misma forma y que los objetivos son los mismos para todos" y E3: "no sé cómo hacer para que todos hagan lo mismo, porque son iguales, pero sin bajar el nivel del que puede hacer más". En este caso, los docentes consideran a la inclusión como sinónimo de integración, en donde la persona con discapacidad se encuentra inmersa en un determinado contexto y es quién tiene que adaptarse al mismo de acuerdo a su desarrollo personal, social y educativo. Para formar parte, necesita alcanzar un determinado nivel previamente definido y estandarizado. La integración ha estado inexorablemente asociada a las personas con discapacidad y el concepto gira alrededor del modelo médico, que considera a las personas como sujetos que tienen algún déficit y que es necesario rehabilitar. En estos discursos no se valora la diversidad de las personas como una realidad natural, sino por el contrario, parten de la premisa que hay que normalizar. 
El concepto de integración difiere de inclusión en cuanto a significado y momento histórico. Para que las personas con discapacidad estén incluidas, deben ser eliminadas las barreras (creencias y actitudes) que impiden el ejercicio efectivo de los derechos (Crisol, 2019). Estas actitudes, se concretan tanto en el macrosistema (a nivel cultural y político) como en el microsistema (familia, escuela, club deportivo, entre otros.).

En el ámbito educativo, "en el año 1994 con la Declaración de Salamanca y el Marco de Acción para las Necesidades Educativas Especiales aprobados por la Conferencia Mundial sobre Necesidades Educativas Especiales se consolida el enfoque de la integración educativa en la educación común, superando el enfoque segregacionista de la educación especial" (Míguez, Angulo, Sánchez, \& Álvarez, 2016, p. 7). La integración escolar a la escuela común, tenía como objetivo incorporar a la persona a la vida escolar y social. Para ello, se adoptaban un conjunto de medidas que buscaban que los alumnos se adaptaran al contexto educativo. Como ejemplo, podemos nombrar a la maestra de apoyo que trabaja con los estudiantes de todas las clases que presentaran algún tipo de dificultad. Pero la idea de normalizar fue muy cuestionada por no respetar las diferencias individuales. No se trata solamente de estar en un determinado lugar, sino realmente formar parte del mismo (Parra, 2010; Romero \& Lauretti, 2006). El modelo de educación integradora fue destacado en su momento, porque rompió con el de escuela segregacionista (escuela especial).

El tránsito de la integración a la inclusión educativa surge luego del Foro Mundial sobre la Educación en el año 2000, que en su marco normativo aparece por primera vez la noción de educación inclusiva (Míguez et al., 2016) enmarcada en el modelo social de discapacidad. Las instituciones educativas verdaderamente inclusivas son las que consideran importante la enseñanza y el aprendizaje, las actitudes y el bienestar de los estudiantes respetando sus características individuales. Ofrecen oportunidades a aquellos que previamente han experimentado dificultades o han sido excluidos (Barrio, 2009; Blanco, 2008; Velásquez, Quiceno, \& TamayoAgudelo, 2016).

En la actualidad, en Uruguay prima la idea de la educación inclusiva (a pesar de persistir las escuelas especiales) y sobre la misma, en la última década se han elaborado políticas que implican el desarrollo de modalidades educativas diversas, con currículos flexibles que permitan atender a la diversidad del estudiantado destacándose la consideración de la inclusión educativa de las personas con discapacidad (Viera \& Zeballos, 2014). En la misma línea están las opiniones de tres entrevistados: “...es adaptar el currículo”(E2); "generar condiciones para que todos puedan participar. No es igualar" (E5); "en la inclusión hay que trabajar teniendo en cuenta las diferencias" (E11).

Por otra parte, en las entrevistas surge la idea de la inclusión como proceso que depende de todos. "Es un proceso que va en desarrollo, que con formación y capacitación creo que se logra, porque necesita de toda la sociedad” (E10). Esta idea es defendida por Ainscow (2005) al explicar que la inclusión es un proceso de mejora de la institución, con la participación de toda la comunidad. El docente agrega que "va de la mano de políticas de estado, no solo por las normas y las leyes sino de todo el entorno" (E10). Al respecto, "el progreso hacia la inclusión requiere voluntad política, acuerdo social basado en valores de equidad y justicia y por lo tanto, no solo depende de la formación del profesorado...” (Durán \& Giné, 2013, p. 157). Urge 
realizar cambios en la organización de los centros, en el diseño y desarrollo del currículum, en la cantidad y distribución de los recursos humanos y materiales, en los sistemas de apoyo y asesoramiento empleados.

Asimismo, la mirada que tienen los entrevistados sobre la inclusión en Educación Física muestra la realidad en la que trabajan diariamente. "En Educación Física faltan entornos adecuados, accesibles. Existen barreras arquitectónicas y también actitudinales. Falta además formación y actitud para incluir" (E10).

Por otra parte, dos entrevistados hacen referencia al programa de educación de primaria o secundaria que tienen que cumplir. "Hay temas obligatorios en el programa y se hace complejo pensar propuestas en que todos puedan participar"(E5). Este planteo lo realiza un docente en el marco de una institución educativa que "desde el discurso tiene una propuesta de inclusión"(E5) y se alinea al artículo 8 de la Ley 18.437 (Ley General de Educación, 2009) que dice: "el Estado asegurará los derechos de aquellos colectivos minoritarios o en especial situación de vulnerabilidad, con el fin de asegurar la igualdad de oportunidades en el pleno ejercicio del derecho a la educación y su efectiva inclusión social". "Como docente tenés que seguir el programa y ver cómo hacer para que todos los alumnos puedan participar" (E2).

En los dos relatos, los entrevistados piensan en la necesidad y dificultad de realizar ajustes para que los estudiantes con discapacidad participen de las actividades propuestas. Para que esto suceda y desde una perspectiva inclusiva, no hay posibilidades de aplicar programas masivos donde todos los alumnos aprendan de la misma forma (Borsani, 2016). Esto está plasmado en el artículo 40 de la Ley 18.651 "Protección Integral de Personas con Discapacidad" (2010) del estado uruguayo donde se expresa que para garantizar la inclusión en todos los niveles del sistema educativo, se utilizarán los apoyos que sean necesarios: flexibilización curricular, mecanismos de evaluación y accesibilidad física y comunicacional.

Para dos entrevistados la inclusión va de la mano con la participación. "Para que esté incluido tiene que estar participando" (E8); "no importa qué discapacidad tiene, lo importante es que forme parte activamente" (E4). Las opiniones de los entrevistados nos remiten a la idea de Aizencang y Bendersky (2013) sobre inclusión. El hecho de que estudiantes con y sin discapacidad convivan en una clase, no nos remite a procesos inclusivos. Hay un sinnúmero de ejemplos que podemos citar de este tipo de situaciones en donde no se emplean los apoyos necesarios, y lo único que hacen es perpetuar las exclusiones dentro del grupo.

Hemos visto que la inclusión supone trasladar el foco de atención del alumno al contexto. La institución educativa debe tener la capacidad de responder a las diversas necesidades que plantean los alumnos. Esa capacidad tiene que reflejarse en el pensamiento de los docentes, en las prácticas educativas y en los recursos personales y materiales disponibles. Los esfuerzos deben dirigirse a la adecuación de las propuestas educativas, y a brindar los apoyos que eventualmente los alumnos puedan precisar (Castillo, 2016; Durán \& Giné, 2012).

Las leyes y las normativas nacionales y las internacionales que Uruguay ratificó, generan un terreno propicio para fortalecer el modelo inclusivo, que debe acompañarse con una respuesta educativa acorde a las individualidades de los alumnos. De lo contrario, podemos caer fácilmente en el discurso de la inclusión y perpetuar prácticas de exclusión. 


\section{Conclusiones}

Hemos presentado a lo largo del estudio, diferentes marcos normativos nacionales e internacionales de los cuáles Uruguay ha acompañado mediante ratificaciones como Estado parte, que dan cuenta de la preocupación en la temática de la inclusión de personas con discapacidad en los diferentes espacios de la sociedad. Para que esto suceda, se necesita de un trabajo en conjunto y de colaboración entre diferentes actores, entre los que incluimos a los docentes.

En este sentido, la formación de grado y posgrado teniendo como eje la diversidad del alumnado, ocupa un lugar preponderante. La diversidad es parte de la condición humana, entender esto, implica crear oportunidades para todos.

Los resultados de esta investigación, muestran que los docentes entrevistados, se desempeñan en educación primaria común y especial, en educación secundaria, en centros de rehabilitación e instituciones donde viven únicamente personas con diferentes discapacidades. Desarrollan su tarea con múltiples objetivos y particularidades que coexisten en una misma clase. En esta línea, los docentes plantean la necesidad de incorporar y/o incrementar la formación en el área de la discapacidad en el grado, así como incluir mayores posibilidades de formación permanente. Sólo cinco de los profesores entrevistados tienen cursos de actualización en el área y en las palabras de los entrevistados se desprende que no se sienten preparados para la enseñanza de alumnos con discapacidad. Sus conocimientos surgen de la experiencia docente, pero no de la formación. A pesar de ello, presentan actitudes positivas ante la discapacidad. De esta manera, el posgrado marca el inicio de un camino que esperemos que perdure en el tiempo y colabore en la mejora de las prácticas docentes.

La terminología que utilizan para referirse a las personas con discapacidad no siempre es la que se enmarca en el modelo social. Persisten en algunos discursos un repertorio de palabras con connotación peyorativa, propio de lo que sucede en la sociedad en su conjunto. La sensibilización en el colectivo docente debería ayudar a erradicar determinados conceptos y conductas estigmatizantes, que aunque los docentes no lo digan explícitamente, en su quehacer educativo se manifiesta.

Constatamos también, las dificultades con las que se enfrentan los docentes al momento de favorecer procesos inclusivos. La falta de formación, de apoyo de la institución en su conjunto, el escaso trabajo multidisciplinario, las actitudes negativas ante la discapacidad y un currículum con contenidos, objetivos y criterios de evaluación que tienen que cumplir con niveles bastantes estancos, son algunos de los aspectos que plantean como dificultades para favorecer la inclusión. También es cierto, que en algunos de sus discursos, aún prima la idea de la inclusión como sinónimo de integración. Pero a pesar de ello, los resultados muestran una predisposición a actuar y a aceptar sin reparos, la participación de estudiantes con y sin discapacidad y también con diferentes discapacidades en una misma clase.

En síntesis, los resultados presentados en este estudio, nos permiten reflexionar sobre la importancia de la formación docente en esta área y cómo ella incide en las concepciones de discapacidad e inclusión, y en el quehacer pedagógico de los profesores en los diferentes ámbitos en los que se encuentran. Pero solo esto no alcanza, un cambio en la mirada implica un 
trabajo en conjunto de la comunidad, que permitan dar respuesta y brindar los apoyos que las personas con discapacidad requieran.

\section{REFERENCIAS}

Abellán, J.; Sáez-Gallego, N., \& Reina, R. (2018). Explorando el efecto del contacto y el deporte inclusivo en Educación Física en las actitudes hacia la discapacidad intelectual de los estudiantes de secundaria. RICYDE - Revista internacional de ciencias del deporte, 53(14), 233-242. DOI: https:// doi.org/10.5232/ricyde2018.05304

Ainscow, M. (2005). Developing inclusive education systems: What are the levers for change? Journal of Educational Change, 6, 109-124. Recuperado el 24 de noviembre de 2018 de https://link.springer. com/article/10.1007/s10833-005-1298-4

Aizencang, N., \& Bendersky. B. (2013). Escuela y prácticas inclusivas: intervenciones psicoeducativas que posibilitan. Buenos Aires: Manantial.

Araya-Cortés, A., González-Arias, M., \& Cerpa-Reyes, C. (2014). Actitud de universitarios hacia las personas con discapacidad. Educación y educadores, 17(2), 289-305. Recuperado el 10 de diciembre de 2018 de http://www.scielo.org.co/scielo.php?script=sci_arttext\&pid=S0123-12942014000200005

Arellano, A., Gaeta, M. L., Peralta, F., \& Cavazos, J. (2019). Actitudes hacia la discapacidad en una universidad mexicana. Revista Brasileira de Educação, 24, 1-20. DOI: http://dx.doi.org/10.1590/ s1413-24782019240023

Bagnato, M. J. (2017). La inclusión educativa en la enseñanza superior: retos y demandas. Educar en Revista, 33(3), 15-26. DOI: http://dx.doi.org/10.1590/0104-4060.51050

Barrio, J. L. (2009). Hacia una Educación Inclusiva para todos. Revista Complutense de Educación, 20(1), 13-31. Recuperado el 24 de enero de 2019 de https://recyt.fecyt.es/index.php/profesorado/article/ view/72108

Bausela, E. (2008). Actitudes hacia la diversidad en un grupo de universitarios de la Universidad Autónoma de San Luis Potosí, México. Revista Científica Electrónica de Psicología, 6, 102-116. Recuperado el 24 de enero de 2019 de http://dgsa.uaeh.edu.mx/revista/psicologia/rubrique. php3?id_rubrique $=6$

Blanco, M. R. (2008). Construyendo las bases de la inclusión y la calidad de la educación en la primera infancia. Revista Educación, 347, 33-54.

Borsani, M. J. (2016). Construir un aula inclusiva: estrategias e intervenciones. Buenos Aires: Paidós.

Castillo, J. (2016). Docente inclusivo, aula inclusiva. Revista nacional e internacional de educación inclusiva, 9(2), 264-275. Recuperado el 15 de marzo de 2019 de http://www.revistaeducacioninclusiva.es/ index.php/REI/article/view/64

Colmenero, M. J., Pantoja, A., \& Pegajalar, M. C. (2015). Percepciones sobre atención a la diversidad en la formación inicial del profesorado en Educación Secundaria. Revista Complutense de Educación, 26(1), 101-120. DOI: http://dx.doi.org/10.5209/rev_RCED.2015.v26.n1.42616

Crisol, E. (2019). Hacía una educación inclusiva para todos. Nuevas contribuciones. Revista de currículum y formación del profesorado, 23(1), 1-9.

Durán, D., \& Giné, C. (2012). La formación del profesorado para la educación inclusiva: Un proceso de desarrollo profesional y de mejora de los centros para atender la diversidad. Revista Latinoamericana de Educación Inclusiva, 5(2), 153-170. 
Echeita, G. (2013). Inclusión y exclusión educativa. De Nuevo "Voz y quebranto". Revista Iberoamericana sobre Calidad, Eficacia y Cambio en Educación, 11(2), 99-118.

Espinoza de los Monteros, M. (2017). Educación inclusiva. Experiencias docentes en la Universidad Metropolitana de Guayaquil. Revista Nacional e Internacional de Educación Inclusiva, 9(1), 45-58. Recuperado el 25 de agosto de 2019 de http://www.revistaeducacioninclusiva.es/index.php/REI/ article/view/282

Fontana-Hernández, A., \& Vargas-Dengo, M. (2018). Percepciones sobre discapacidad: Implicaciones para la atención educativa del estudiantado de la Universidad Nacional de Costa Rica. Revista Electrónica Educare, 22(3) 1-24. DOI: http://dx.doi.org/10.15359/ree.22-3.16

Gentili, P. (2009). Marchas y contramarchas. El derecho a la educación y las dinámicas de exclusión incluyente en América Latina (a sesenta años de la declaración universal de los derechos humanos). Revista Iberoamericana de Educación, 49, 19-57.

González-Gil, F., Martín-Pastor, E., \& Poy Castro, R. (2019). Educación inclusiva: barreras y facilitadores para su desarrollo. Análisis de la percepción del profesorado. Revista de currículum y formación del profesorado, 23(1), 243-263. DOI: https://doi.org/10.30827/profesorado.v23i1.9153

González, J., \& Baños, L. M. (2012). Estudio sobre el cambio de actitudes hacia la discapacidad en clases de actividad física. Cuadernos de Psicología del Deporte, 12(2), 101-108. DOI: https://doi. org/10.4321/S1578-84232012000200011

González, I., \& Macías, D. (2018). La formación permanente como herramienta para mejorar la intervención del maestro de educación física con alumnado con discapacidad. Retos. Nuevas tendencias en educación física, deporte y recreación, 33, 118-122. Recuperado el 25 de agosto de 2019 de https://recyt.fecyt.es/index.php/retos/article/view/55056.

Hernández, F. J., Labrador, V., Niort, J., Berbel, G., \& Trullols, M. (2017). Respuesta del profesorado de Educación Física ante conflictos con alumnado con discapacidad intelectual y física. Retos, 31, 123-127. Recuperado el 20 de marzo de 2019 de https://dialnet.unirioja.es/servlet/ articulo?codigo $=5841357$

Instituto Universitario Asociación Cristiana de Jóvenes (2011). Revisión curricular. Montevideo: IUACJ.

Ley $n^{\circ}$ 18.437, de 16 de enero de 2009. Ley General de Educación. Recuperado el 20 de marzo de 2019 de https:/www.ineed.edu.uy/images/pdf/-18437-ley-general-de-educacion.pdf

Ley $n^{\circ}$ 18.651, de 9 de marzo de 2010. Protección integral de personas con discapacidad. Recuperado el 20 de marzo de 2019 de https://legislativo.parlamento.gub.uy/temporales/leytemp1480166.htm

Marradi, A., Archenti, N., \& Piovani, J. I. (2007). Metodología de las ciencias sociales. Buenos Aires: Emecé.

Martins, C. L. R. (2014). Educação Física inclusiva: atitudes dos docentes. Movimento, Porto Alegre, 20(2), 637-657.

Míguez, M. N., Angulo, S., Sánchez, L., \& Álvarez, T. (2016). Educación y Discapacidad en Uruguay. Tensiones y Desafíos. Llamado del Fondo Universitario para contribuir a la comprensión pública de temas de interés general, 1-11. Recuperado el 23 de enero de 2019 de http://cienciassociales.edu. uy/wp-content/uploads/sites/5/2016/08/Proyecto-Art.-2-Educaci\%C3\%B3n-y-Discapacidad-enUruguay-Tensiones-y-desaf\%C3\%ADos.pdf

Ministerio de Educación y Cultura. Administración Nacional de Educación Pública. (2012). Buenas prácticas en educación inclusiva en Uruguay. Montevideo: ANEP. 
Moreno, J., Rodríguez, I., Saldaña D., \& Aguilera, A. (2006). Actitudes ante la discapacidad en el alumnado universitario matriculado en materias afines. Revista Iberoamericana de Educación, 40(5), 1-12.

Nuñez, I. (2014). Personas con discapacidad en Uruguay: algunas cifras del censo 2011. Montevideo: Asesoría en Políticas de Seguridad Social. Asesoría General en Seguridad Social.

Oliveira, S. S., \& Barros, K. R. S. (2012). Desafios e dificuldades na formação do professor diante de alunos com deficiência inseridos em salas regulares. Anais da Semana da Educação da Universidade Estadual de Londrina, Londrina, Brasil.

Oliveira, S. E.; Silva, T. P.; Padilha, M. A. O., \& Bomfim, S. R. (2012). Inclusão social: professores preparados ou não? Polêmica - Revista Eletrônica, 11(2), 314-323. Recuperado el 23 de agosto de 2019 de https://www.e-publicacoes.uerj.br/index.php/polemica/article/view/3103/2224

Organización Mundial de la Salud. (1983). Clasificación internacional de deficiencias, discapacidades y minusvalías. Madrid: Inserso.

Organización Mundial de la Salud. (2001). Clasificación internacional del funcionamiento de la discapacidad $y$ de la salud: CIF. Madrid, Espańa: Ministerio de Trabajo y Asuntos Sociales. Recuperado el 4 de noviembre de 2018 de http://ccp.ucr.ac.cr/bvp/pdf/desarrollohumano/oms-clasificacion-01.pdf.

Organización de las Naciones Unidas. (2006). Convención internacional sobre los derechos de las personas con discapacidad. Recuperado el 4 de noviembre de 2018 de http:/www.un.org/spanish/disabilities/ default.asp?id=497

Palacios, A. (2008). El modelo social de discapacidad: orígenes, caracterización y plasmación en la Convención Internacional sobre los Derechos de las Personas con Discapacidad. Madrid: Editorial Cinca.

Palla, A. C., \& Mauerberg-deCastro, E. (2004). Atitudes de Professores e Estudantes de Educação Física em Relação ao Ensino de Alunos com Deficiência em Ambientes Inclusivos. Revista da Sociedade Brasileira de Atividade Motora Adaptada, 9(1), 25-34.

Parra, C. (2010). Educación inclusiva: un modelo de educación para todos. Revista ISEES, Chile, 8, 73-84.

Plancarte, P. (2017). Inclusión educativa y cultura inclusiva. Revista Nacional e Internacional de Educación Inclusiva, 10(2), 213-226. Recuperado el 14 de marzo de 2019 de http://www. revistaeducacioninclusiva.es/index.php/REI/article/view/294

Querejeta, M. (2003). Discapacidad/dependencia: unificación de criterios de valoración y clasificación. Madrid: Ministerio de Trabajo y Asuntos Sociales.

Rello, C. F., \& Garoz, I. (2014). Actividad físico-deportiva en programas de cambio de actitudes hacia la discapacidad en edad escolar: Una revisión de la literatura. Cultura, Ciencia y Deporte, 9(10), 199-210.

Rello, C. F., Garoz, I., \& Tejero, C. M. (2018). Análisis comparativo del efecto de tres programas de sensibilización hacia la discapacidad en Educación Física. Retos, 34, 258-262.

Romero, R., \& Lauretti, P. (2006). Integración educativa de las personas con discapacidad en Latinoamérica. Revista Educere, 10(33), 347-356. Recuperado el 4 de enero de 2019 de https:// www.researchgate.net/publication/28121886_Integracion_educativa_de_las_personas_con_ discapacidad_en_Latinoamerica

Rubinstein, S. (2012). La formación en el área de la discapacidad de los profesores de Educación Física: un análisis de los planes de estudios de 1992, 1996 y 2004 del curso de profesores del ISEF Montevideo. Movimento, 18(3), 203-218. 
Salerno, M., Jordan, M. A., \& Araújo, P. (2015). Instituciones de enseñanza superior de España y Brasil: temática sobre las personas con discapacidad. Revista Brasileira de Educação Física e Esporte, São Paulo, 29(2), 303-312. Recuperado el 5 de febrero de 2019 de http://www.revistas.usp.br/rbefe/ article/view/99804

Santos, S. D. G., Fumes, N. L. F., \& Ferreira, J. P. (2015). Experiência e formação dos professores de Educação Física das Universidades de Portugal na perspectiva inclusiva. Revista da Sociedade Brasileira de Atividade Motora Adaptada, 16(2), 9-14. Recuperado el 25 de enero de 2019 de http:// www.sobama.org.br//arquivos/revistas/sobama/sobama-2015-16-2.pdf

Sautu, R. (2003). Todo es Teoría: objetivos y métodos de investigación. Argentina: Lumiere.

Sosa, L. (2010). La formación profesional en Educación Física sobre discapacidad. Educación Física Argenmex: temas y posiciones. Recuperado el 14 de diciembre de 2018 de http://www.argenmex. fahce.unip.edu.ar

Sosa, L. (2009). Reflexiones sobre la discapacidad: dialógica de la inclusión y exclusión en las prácticas. Ágora para la EF y el Deporte, 9, 57-82. Recuperado el 17 de enero de 2019 de https://dialnet. unirioja.es/servlet/articulo?codigo $=2900332$

Urrego Gallego J. de D., \& Urrego Gallego, H. (2007). El problema de la discapacidad y la inclusión educativa y social. In E.D. Eusse Castro (Ed.), Educación Física y Discapacidad. Prácticas corporales inclusivas (pp. 81-92). Medellín: Funámbulos Editores.

Valdés, A. M., \& Monereo, C. (2013). Desafíos a la formación del docente inclusivo: La identidad profesional y su relación con los incidentes críticos. Revista Latinoamericana de Inclusión Educativa, 6(2), 193-208.

Vallejos, I., Kipen, E., Almeida, M. E., Spadillero, A. Fernández, M. E., Angelino, A., ... Zuttión, B. (2015). La producción social de la discapacidad. Aportes para la transformación de los significados socialmente construidos. In P. Vain (Coord.), Comunidad, discapacidad y exclusión social. La construcción social de la normalidad. Alteralidades, diferencias y diversidad (pp. 31-40). Buenos Aires: Noveduc.

Velásquez, Y., Quiceno, E., \& Tamayo-Agudelo, W. (2016). Construcción de planeaciones pedagógicas para la educación inclusiva. Actualidades Investigativas en Educación, 16(3) 1-36. DOI: http:// dx.doi.org/10.15517/aie.v16i3.26113

Verdugo, M. Á. (2005). Personas con deficiencias, discapacidades y minusvalías. In M. À. Verdugo (Dir.), Personas con discapacidad: perspectivas psicopedagógicas y rehabilitadoras (4a ed., pp. 81-88) Madrid: Siglo XXI.

Viera, A., \& Zeballos, Y. (2014). Inclusión educativa en Uruguay; una revisión posible. Revista Psicología, Conocimiento y Sociedad, Montevideo, 4(2), 237-260. Recuperado el 10 de febrero de 2019 de https://revista.psico.edu.uy/index.php/revpsicologia/issue/view/44

Yuker, H. (1988). Attitudes toward persons with disabilities. Nueva York: Springer.

Submetido em 02/04/2019

Reformulado em 26/09/2019

Aceito em 30/09/2019 
RUBINSTEIN, S. \& FRANCO, V. 